\title{
The inter-observer reproducibility of Shafer's sign
}

\begin{abstract}
Pigment cells in the anterior vitreous (Shafer's sign) are known to be associated with retinal breaks. We sought to identify the reproducibility of Shafer's sign between different grades of ophthalmic staff. In all 47 patients were examined by a consultant vitreoretinal surgeon, a senior house officer (SHO) and optician for Shafer's sign.

Cohen's kappa for consultant vs SHO assessment of Shafer's sign was 0.55 while for consultant $v$ s optician assessment, kappa was 0.28 .

Retinal tears were present in $63.8 \%$ of our series. Consultant assessment of Shafer's sign with fundoscopy findings, we found specificity to be $93.5 \%$ while sensitivity was 93.8\%. Kappa for consultant assessment of Shafer's sign $v$ s break presence was 0.86 . Consultant and SHO assessment of Shafer's sign is of moderate agreement while optician assessment is fair. These results suggest a relationship between training and the assessment of Shafer's sign. We feel this study suggests caution in undue reliance on Shafer's sign particularly for inexperienced members of staff.

Eye (2009) 23, 661-662; doi:10.1038/eye.2008.9; published online 29 February 2008
\end{abstract}

Keywords: Shafer's sign; retinal break; training; reproducibility

Pigment cells in the anterior vitreous (Shafer's sign $)^{1}$ are known to be associated with retinal breaks. We sought to identify the reproducibility of Shafer's sign between different grades of ophthalmic staff.

The anterior vitreous of 47 patients was examined for pigment cells. Each patient was examined by a consultant vitreo-retinal surgeon (RRG), a senior house officer, and optician. Junior staff were of mixed experience levels. None had had any specific vitreo-retinal training.
F Qureshi and R Goble

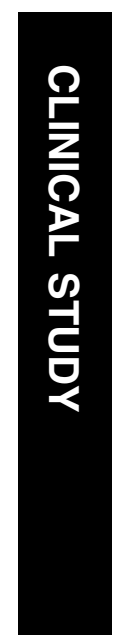

Agreement was found between consultant and senior house officer (SHO) assessment in $78.2 \%$ (36/46 cases) (Table 1). Cohen's kappa for consultant vs SHO assessment was 0.55 (95\% confidence interval 0.32-0.80).

Agreement between consultant and optician assessment was found in $61.7 \%$ (29/46 cases) (Table 2). Cohen's kappa for consultant vs optician assessment was 0.28 (95\% CI 0.02-0.54).

Retinal tears were present in 63.8\% (30/47 cases) of our series (Table 3). Comparing the consultant assessment of Shafer's sign with funduscopy findings, we found specificity to be 93.5\% (95\% CI 84.7-100\%) while sensitivity was 93.8\% (95\% CI 81.6-100\%). Kappa for consultant assessment of Shafer's sign vs break presence was 0.86 (95\% CI 0.70-1.00).

A history of severe blunt trauma was present in two cases.

Our series compare well with previously published data. $^{2-5,7}$

The agreement between consultant assessment of Shafer's sign and break presence is good. ${ }^{6}$ Our series contained two false positives, one presumably due to severe blunt trauma, the other misread due to clumps of vitreous haemorrhage. The false negative had an atrophic hole. The vitreous haemorrhage was excluded from $\mathrm{SHO}$ and optometrist assessment.

Our Kappa indices indicate that the agreement between $\mathrm{SHO}$ assessments of Shafer's sign is of moderate agreement with the consultant's, while optician assessment is fair. ${ }^{6}$ It can be seen from Tables 1 and 2 that it was the junior 'false-negatives' that were the largest source of disagreement suggesting that difficulties lay in detecting a positive Shafer's sign. These results suggest a relationship
Department of Ophthalmology, Ipswich Hospital, Ipswich, Suffolk, UK

Correspondence: F Qureshi, Department of Ophthalmology, Ipswich Hospital, Ipswich,

Suffolk

IP4 5PD,

UK

Tel: + 014737122 33;

Fax: + 01473703838

E-mail: farhanqureshi101@ hotmail.com

Received: 3 January 2007 Accepted in revised form: 2 January 2008 Published online: 29 February 2008 
Table 1 Consultant vs SHO assessments of Shafer's sign

\begin{tabular}{lccc}
\hline$R G$ & \multicolumn{2}{c}{ SHO } & Total \\
\cline { 2 - 3 } & Positive & Negative & \\
\hline Positive & 22 & 8 & 30 \\
Negative & 2 & 14 & 16 \\
Total & 24 & 22 & 46
\end{tabular}

Table 2 Consultant $v$ s optician assessments of Shafer's sign

\begin{tabular}{|c|c|c|c|}
\hline \multirow[t]{2}{*}{$R G$} & \multicolumn{2}{|c|}{ Optician } & Tota \\
\hline & Positive & Negative & \\
\hline Positive & 17 & 13 & 30 \\
\hline Negative & 4 & 12 & 16 \\
\hline Total & 21 & 25 & 4 \\
\hline
\end{tabular}

between training and the assessment of Shafer's sign. We feel this study suggests caution in undue reliance on Shafer's sign particularly for inexperienced members of staff.

\section{References}

1 Shafer DM, Stratford DP. Binocular indirect ophthalmoscopy In: Schepens CL, Regan CDJ, (eds). Controversial Aspect of the
Table 3 Consultant assessments of Shafer's sign vs break detection

\begin{tabular}{lccc}
\hline$R G$ & \multicolumn{2}{c}{ Break } & Total \\
\cline { 2 - 3 } & Present & Absent & \\
\hline Positive & 29 & 2 & 30 \\
Negative & 1 & 15 & 16 \\
Total & 30 & 17 & 47 \\
\hline
\end{tabular}

Management of Retinal Detachment. J \& A Churchill: London, 1965, p 51.

2 Tanner V, Harle D, Tan J, Foote B, Williamson T, Chignell A. Acute posterior vitreous detachment: the predictive value of vitreous pigment and symptomatology. Br J Ophthalmol 2000; 84: 1264-1268.

3 Brod R, Lightman D, Packer A, Saras H. Correlation between vitreous pigment granules and retinal breaks in eyes with acute posterior vitreous detachment. Ophthalmology 1991; 98: 1366-1369.

4 Hamilton A, Taylor W. Significance of pigment granules in the vitreous. Brit J Ophthal 1972; 56: 700-702.

5 Hikichi T, Trempe C. Relationship between floaters, light flashes, or both, and complications of posterior vitreous detachment. Am J Ophthalmol 1994; 117: 593-598.

6 Altman DG. Practical Statistics for Medical Research. CRC: Chapman and Hall, 1991, p 404.

7 Lightman D. Relationship between floaters, light flashes, or both, and complications of posterior vitreous detachment. Am J Ophthalmol 1994; 118(5): 683-684. 